\title{
FORUM KORDINASI PENANGGULANGAN TERORISME (FKPT) DAN GERAKAN DERADIKALISASI AGAMA DI INDONESIA: STUDI KASUS DI MALUKU
}

\author{
Abd. Rauf \\ Fakultas Syariah dan Ekonomi Islam IAIN Ambon \\ Email: raufbasry@yahoo.com
}

\begin{abstract}
ABSTRAK:
Salah satu cara terbaik dalam pemberantasan terorisme adalah dengan program deradikalisasi. Deradikalisasi merupakan upaya menetralisir paham radikal bagi mereka yang terlibat teroris dan para simpatisannya serta anggota masyarakat yang telah terekspos paham-paham radikal, melalui reedukasi dan resosialisasi serta menanamkan multikuralisme. Langkah strategis dalam implementasi dan sosialisasi program deradikalisasi di daerah adalah dengan melibatkan organisasi-organisasi masyarakat sipil Indonesia, mengingat lingkungan sosial adalah locus utama bagi penyebaran benih-benih radikalisme. Dalam konteks inilah peran Forum Kordinasi Pencegahan Terorisme (FKPT) menjadi sangat strategis. Dengan melibatkan FKPT sebagai representasi publik/masyarakat sipil, pelaksanaan program deradikalisasi menjadi lebih efektif dalam jangka panjang.

Kata kunci: FKPT, deradikalisasi agama, terorisme.
\end{abstract}

\begin{abstract}
:
One of the best ways to eradicate terrorism is through de-radicalization programs. Deradicalization is an attempt to neutralize radical notions for those involved in terrorists and their sympathizers and community members who have been exposed to radical understandings, through reeducation and resocialization and instilling multiculturalism. Strategic steps in the implementation and dissemination of deradicalization programs in the regions are by involving Indonesian civil society organizations, given that the social environment is the main locus for the spread of seeds of radicalism. In this context the role of the Terrorism Prevention Coordination Forum (FKPT) has become very strategic. By involving FKPT as a public/civil society representation, the implementation of deradicalization programs has become more effective in the long term.
\end{abstract}

Keywords: FKPT, religious de-radicalization, terrorism.

\section{Pendahuluan}

Era reformasi melahirkan perkembangan penting pada masyarakat Islam, salah satunya adalah munculnya kelompok Muslim radikal (hardliners). ${ }^{1}$ Pasca reformasi yang ditandai dengan terbukanya kran demokratisasi telah menjadi lahan subur

\footnotetext{
${ }^{1}$ Arskal Salim dan Azyumardi Azra, "Introduction: The State and Shari'a in the Perspective of Indonesian Legal Politics," Sharia and Politics in Modern Indonesia, ed. Arskal Salim and Azyumardi Azra, (Singapore: Institute of Southeast Asian Studies, 2003).
} 


\section{Tahkím}

Vol. XIV, No. 2, Desember 2018

tumbuhnya kelompok Islam radikal. ${ }^{2}$ Menurut Arsyad Mbai, terdapat lima tipologi kelompok radikal yang muncul pada masa itu yaitu radikal gagasan (Hizbut Tahrir Indonesia/HTI, Majelis Mujahidin Indonesia/MMI), radikal nonteroris (Front Pembela Islam/FPI), radikal milisi (Laskar Jihad), radikal separatis (Negara Islam Indonesia/ NII), dan radikal teroris (Jama'ah Islamiyah). ${ }^{3}$

Cukup banyak data terbaru tentang radikalisme dan terorisme yang terjadi belakangan. Tahun 2011 terjadi aksi bom buku, bom bunuh diri di masjid Mapolresta Cirebon, bom di Serpong dan bom bunuh diri di Kepunton Solo. Pertengahan tahun 2012, terjadi teror bom di pos penjagaan polisi di Gladak Solo, ${ }^{4}$ lalu diikuti dengan penembakan terhadap pengendara motor yang diduga pelaku teror. ${ }^{5}$ Tahun 2013 terjadi perburuan Densus 88 terhadap jaringan teroris Poso di Makassar. ${ }^{6}$ Penembakan terhadap terduga teroris juga terjadi di awal tahun 2014 di Ciputat Banten. ${ }^{7}$ Kasus terorisme terbaru terjadi pada 14 Januari 2016 lalu di Starbucks Coffee dan kawasan Sarinah, Jalan MH Thamrin, Jakarta Pusat, menewaskan 8 orang dan 26 orang lainnya terluka. Ini adalah keprihatinan bersama bangsa Indonesia dan perlu "diperangi" oleh segenap masyarakat di tanah air untuk meminimalkan aksi-aksi terorisme itu terjadi lagi. Data di atas menunjukkan bahwa radikalisme yang berpuncak pada aksi terorisme merupakan masalah serius yang patut dikaji lebih dalam.

Berdasarkan uraian di atas, diperlukan langkah-langkah antisipatif untuk mengurangi atau bahkan menghilangkan bibit radikalisme Islam. Deradikalisasi merupakan kerja lanjutan setelah diketahui akar radikalisme paham Islam radikal. Deradikalisasi adalah segala upaya untuk menetralisir paham-paham radikal melalui pendekatan interdisipliner, seperti hukum, psikologi, agama, dan sosial-budaya bagi mereka yang dipengaruhi atau terekspose paham radikal dan prokekerasan. Deradikalisasi terorisme ini diwujudkan dengan program reorientasi motivasi, reedukasi, resosialisasi, serta mengupayakan kesejahteraan sosial dan kesetaraan dengan masyarakat lain bagi mereka yang pernah terlibat terorisme maupun bagi simpatisan, sehingga timbul rasa nasionalisme dan mau berpartisipasi dengan baik sebagai Warga Negara Indonesia (WNI).

Meskipun deradikalisasi telah menjadi kebijakan nasional yang harus dilakukan, sampai saat ini istilah deradikalisasi masih cukup kontroversial. Tidak semua umat Islam menyetujui 'proyek' deradikalisasi. Sebagai contoh, Sekjen Forum Umat Islam

\footnotetext{
${ }^{2}$ Greg Fealy and Virginia Hooker (ed.), Voices of Islam in Southeast Asia: A Contemporary Sourcebook, (Singapore: ISEAS, 2006), h. 4.

${ }^{3}$ Disampaikan pada Dialog Publik Radikalisme, Terorisme dan Deradikalisasi Paham Radikal, diselenggarakan MUI Jawa Tengah, 3 Desember 2011.

${ }^{4}$ Solo Pos, 19 Agustus 2012.

${ }^{5}$ Tempo.co.id, 4 September 2012.

${ }^{6}$ Banjarmasin Post.co.id, 21 Pebruari 2013.

${ }^{7}$ Majalah.tempo.co.id, 13 Januari 2014.
} 


\section{Tahkím}

Vol. XIV, No. 2, Desember 2018

(FUI), M. Al-Khaththath menganggap deradikalisasi agama sebagai ancaman dan teror baru bagi umat Islam. ${ }^{8}$

Dalam pelaksanaannya, program deradikalisasi merupakan tangungjawab dari Badan Nasional Penanggulangan Terorisme (BNPT) yang dibentuk oleh pemerintah pada tahun 2010 melalui Perpres No. 46 Tahun 2010. Tugas utama BNPT adalah penanggulangan terorisme, meliputi pencegahan, perlindungan, deradikalisasi, penindakan, dan penyiapan kesiap-siagaan nasional (Pasal 2). Sedangkan salah satu fungsinya adalah koordinasi dalam pencegahan dan pelaksanaan kegiatan melawan propaganda ideologi radikal di bidang penanggulangan terorisme (Pasal 3). Atas dasar itu, maka deradikalisasi telah menjadi kebijakan nasional yang harus dilakukan, termasuk meminta peran serta dari masyarakat.

Dalam implementasinya, BNPT melakukan program deradikalisai dalam dua cara; deradikalisasi dalam lapas dan deradikalisasi luar lapas. Untuk jenis pertama, target utamanya jelas adalah para napi terorisme yang menghuni rumah tahanan. Dalam program ini para napi terorisme diajak untuk berdiskusi, berdialog, dan bahkan berdebat (jika perlu) tentang pemahaman keagamaan yang keliru. Mereka kemudian dibekali dengan berbagai keahlian yang akan mereka gunakan untuk hidup di jalan yang benar kelak ketika kembali ke masyarakat. Sementara deradikalisasi di luar lapas ditujukan kepada masyarakat umum, utamanya keluarga dan sanak saudara para terpidana terorisme. Para keluarga dan sanak saudara ini termasuk dalam golongan dengan potensi terpapar radikalisme dan terorisme yang tinggi, karenanya mereka masuk dalam ring satu (sasaran utama) program pencegahan, jangan sampai mereka terkena bujuk rayu dan tipuan murahan radikalisme.

Masyarakat luas juga tidak luput dari program deradikalisasi, karena program ini menyasar ke berbagai jenjang, terdapat setidaknya lima golongan yang menjadi sasaran program, yakni potensi teroris (masyarakat yang berpotensi menjadi pelaku teror), mantan teroris, mantan napi teroris, keluarganya dan jaringannya. Dalam rangka melibatkan masyarakat luas dalam program deradikalisasi, BNPT juga membentuk Forum Koordinasi Pencegahan Terorisme (FKPT) untuk mencegah penyebaran paham radikal di seluruh Indonesia. Selanjutnya, FKPT menjadi perpanjangan tangan dari BNPT dalam memonitor pergerakan dan ancaman radikalisme dan terorisme di daerah. FKPT merupakan andalan BNPT di daerah dan garda terdepan dengan senjata kearifan lokal dalam mencegah kemungkinan aksi terorisme di Indonesia. Dengan demikian, FKPT berperan dalam membantu memonitor, memantau, serta menyerap masukan dari masing-masing daerah. FKPT juga berperan dalam deteksi dini bahaya terorisme.

Studi ini dilakukan untuk mengkaji lebih dalam peran dan keterlibatan FKPT di daerah, khususnya di Maluku (FKPT Maluku) dalam program deradikalisasi yang

${ }^{8}$ Abu Rokhmad, "Radikalisme Islam dan Upaya Deradikalisasi Paham Radikal," Walisongo, Vol. 20, No. 1, Mei 2012, h. 79-114 


\section{Tahkím}

Vol. XIV, No. 2, Desember 2018

dilakukan oleh BNPT. Kajian ini diperlukan oleh karena setiap pelaku radikalisme bersifat unik dan berbeda antara satu dengan yang lainnya. Pada akhirnya kajian ini diharapkan dapat memberi gambaran tentang kegiatan deradikalisasi di daerah dan melahirkan sebuah model bagi kerja deradikalisasi, baik untuk deradikalisasi pencegahan maupun penyembuhan di Indonesia.

\section{Radikalisme dan Deradikalisasi}

\section{Radikalisme}

\section{a. Konsepsi Radikalisme}

Kamus Besar Bahasa Indonesia (KBBI) mengartikan radikalisme sebagai: "1. Paham atau aliran yang radikal dalam politik; 2 . Paham atau aliran yang menginginkan perubahan atau pembaharuan sosial dan politik dengan cara kekerasan atau drastis; dan 3. Sikap ekstrem dalam aliran politik." Berdasarkan definisi tersebut, secara harfiah, radikalisme sesungguhnya tidak memiliki sesuatu yang negatif. Namun secara etimologi, radikalisme telah mengalami penyempitan makna yang bermakna negatif. Radikalisme merupakan paham (isme), tindakan yang melekat pada seseorang atau kelompok yang menginginkan perubahan baik, sosial, politik dengan menggunakan kekerasan, berfikir asasi dan bertindak ekstrem. ${ }^{9}$

Kata 'radikal' disandingkan dengan Islam menjadi 'radikalisme Islam', maka itu berarti seseorang yang benar-benar dengan sepenuh hati dan tenaga serta pikiran yang mendukung, berpihak, atau menjadi ekstrim terhadap ajaran agama Islam, melebihi orang-orang Islam pada umumnya.

Radikalisme Islam adalah gerakan yang berpandangan kolot dan sering menggunakan kekerasan dalam mengajarkan keyakinan mereka. ${ }^{10}$ Fealy dan Hooker mendefinisikan Islam radikal (radical Islam) sebagai gerakan Islam yang hendak melakukan perubahan dramatis baik di masyarakat maupun Negara. ${ }^{11}$ Kelompok yang berpandangan seperti itu, selain disebut Islam radikal juga digunakan istilah neokhawarij. ${ }^{12}$ Al-Jabiri menggunakan istilah ekstrimisme untuk menggambarkan kelompok Islam radikal. Bahkan Al-Jabiri menyebutkan bahwa musuh bebuyutan Islam ekstrem adalah kelompok yang paling dekat dengannya, yaitu Islam moderat. ${ }^{13} \mathrm{Al}-$ Asymawi juga menggunakan istilah ekstrimisme untuk menyebut kelompok yang ingin merebut kekuasaan dengan menunggangi isu agama. ${ }^{14}$

\footnotetext{
${ }^{9}$ Bachtiar Effendy, Radikalisme: Sebuah Pengantar (Jakarta: PPIM, 1998), h. xvii-xviii.

${ }^{10}$ Harun Nasution. Islam Rasional. (Bandung: Mizan, 1995), h. 124.

${ }^{11}$ Greg Fealy and Virginia Hooker (ed.), Voices of Islam in Southeast Asia: A Contemporary Sourcebook, (Singapore: ISEAS, 2006), h. 4.

12 Jafar M. Sidik, "Terorisme, Semiotika dan Bahasa Indonesia" dalam Kompas, 6 Oktober 2010.

${ }^{13}$ Muhammad Abid Al-Jabiri, Agama, Negara dan Penerapan Syariah. (Yogyakarta: Pustaka Pelajar, 2001), h.139-149.

${ }^{14}$ Muhammad Said Al-Asymawi, Al-Islam al-Siyasi. (Kairo: Sina li al-Nasyr, 1987), h. 66. 


\section{Tahkím}

Vol. XIV, No. 2, Desember 2018

\section{b. Faktor-Faktor Penyebab Munculnya Radikalisme}

Secara umum, munculnya radikalisme disebabkan oleh beberapa faktor, seperti yang dikutip dari buku Kapita Selekta Sosiologi Agama. ${ }^{15}$ Pertama, faktor-faktor sosial-politik. Gejala kekerasan "agama" lebih tepat dilihat sebagai gejala sosialpolitik daripada gejala keagamaan. Kedua, faktor emosi keagamaan. Harus diakui bahwa salah satu penyebab gerakan radikalisme adalah faktor sentimen keagamaan, termasuk di dalamnya adalah solidaritas keagamaan untuk kawan yang tertindas oleh kekuatan tertentu. Ketiga, faktor kultural, yang dimaksud faktor kultural di sini adalah sebagai anti-tesa terhadap budaya sekularisme. Keempat, faktor ideologis anti westernisme. Kelima, faktor kebijakan pemerintah. Di luar dua faktor di atas, sebagian kecil informan menyebut adanya faktor kemiskinan, dan kesenjangan sosial.

\section{c. Tahapan Radikalisasi}

Dalam tulisan "Radicalization in The West: The Homegrown Threat," Mitchell Silber dan Arvin Bhatt, dua orang analis senior di Divisi Intelijen New York Police Department menawarkan pendekatan untuk melihat bagaimana proses radikalisasi terjadi, Silber dan Bhatt menawarkan empat tahapan proses radikalisasi, yaitu: (1) PraRadikalisasi, (2) Identifikasi Diri, (3) Indoktrinasi, (4) Jihadisasi. ${ }^{16}$

\footnotetext{
${ }^{15}$ Subair, Kapita Selekta ..., h. 48

${ }^{16}$ Mitchell D. Silber and Arvin Bhatt, Radicalization in the West : The Homegrown Threat, (New York : New York Police Department Intelligence Division, 2007), h. 16
} 


\section{Tahkím}

Vol. XIV, No. 2, Desember 2018

\section{Deradikalisasi}

\section{a. Konsepsi Deradikalisasi}

Deradikalisasi secara bahasa berasal dari kata "radikal" yang mendapat imbuhan "de" dan akhiran "sasi". Maka yang dimaksud "deradikalisasi" adalah sebuah langkah untuk merubah sikap dan cara pandang yang dianggap keras menjadi lunak; toleran, pluralis, moderat dan liberal. Deradicalization dengan imbuhan awal "de" dalam bahasa Inggris memiliki arti, "opposite, reverse, remove, reduce, get off” (kebalikan atau membalik), kemudian imbuhan akhir yang dilekatkan pada kata "radikal" menjadi radicalize, akhiran "ize", berarti, "cause to be or resemble, adopt or spread the manner of activity or the teaching of" (suatu sebab untuk menjadi atau menyerupai, memakai atau penyebaran cara mengajari). Sehingga dalam imbuhan "de" tidak mengalami perubahan bentuk. Sedangkan imbuhan akhir "ize" menjadi "isasi", yang memberikan makna proses atau upaya untuk menghilangkan radikalisme. ${ }^{17}$

Dalam konteks perang terhadap terorisme, konsep deradikalisasi, harus dijadikan sebagai "kontra-ideologi (radikalisme) terorisme" yang melembaga (dan membudaya) dalam kehidupan masyarakat sampai pada lapisan paling terbawah. Konsep deradikalisasi perlu diperkuat dengan komitmen pemerintah untuk meniadakan ketidakadilan sosial dan ekonomi masyarakat. ${ }^{18}$

\section{b. Pendekatan-pendekatan dan Strategi dalam Deradikalisasi}

Dalam konteks deradikalisasi di Indonesia, Mohammad AS Hikam mengusulkan agar Pemerintah menerapkan pendekatan-pendekatan normatif bagi program deradikalisasi yang berorientasi pada MSI sebagai berikut:

1. Pendekatan humanis, yaitu memberikan perhatian kepada aspek HAM sebagaimana telah diratifikasi oleh negara.

2. Pendekatan komunikasi sosial, yaitu suatu pendekatan yang memberikan tekanan kepada komunikasi sinergis dan sejauh mungkin mempergunakan prinsip anti kekerasan dan non- intimidasi.

3. Pendekatan partisipatif dari elemen-elemen masyarakat. Dengan pendekatan ini dimaksudkan agar program deradikalisasi tidak hanya ditujukan khusus kepada sasaran yang terdiri atas para tersangka atau terpidana terorisme, melainkan juga bisa diterapkan kepada lingkungan masyarakat di mana potensi radikalisme bisa muncul setiap waktu. ${ }^{19}$

\footnotetext{
${ }^{17}$ M. Marwan dan Jimmy P, Kamus Hukum, (Surabaya: Reality Publisher, 2009), h. 519

18 Romli Atmasasmita, "Deradikalisasi dan Tindak Pidana Terorisme," Harian Seputar Indonesia, 25 April 2011.

${ }^{19}$ Muhammad AS Hikam. Deradikalisasi: Peran Masyarakat Sipil Indonesia Membendung Radikalisme. Jakarta: Penerbit Buku Kompas, 2016, hlm. 81-82
} 


\section{Tahkím}

Vol. XIV, No. 2, Desember 2018

\section{Forum Koordinasi Pencegahan Terorisme (FKPT) Maluku}

\section{Profil Forum Kordinasi Pencegahan Terorisme (FKPT) Maluku}

FKPT dibentuk agar terjalin sinergi dalam upaya pencegahan terorisme di daerah dengan melibatkan seluruh unsur masyarakat dan pemerintah daerah. Para pengurus FKPT terdiri dari para tokoh masyarakat, akademisi, tokoh adat, tokoh ormas, tokoh media, tokoh pemuda, tokoh perempuan, dan unsur pemerintah daerah. FKPT mengemban tugas untuk mengantisipasi berbagai hal negatif terkait ideologi, radikalisme dan terorisme di masyarakat.. Dasar pembentukan FKPT yakni Peraturan Presiden RI Nomor 46 tahun 2010 sebagaimana telah direvisi melalui Peraturan Presiden RI Nomor 12 tahun 2012 tentang Badan Nasional Penanggulangan Terorisme dan Peraturan Kepala Badan Nasional Penanggulangan Terorisme Nomor 02 Tahun 2012 Tentang Pembentukan Forum Koordinasi Pencegahan Terorisme di Daerah. Dalam menjalankan tugasnya untuk mencegah terorisme di Wilayah NKRI, FKPT bersifat koordinatif dan nonpartisan, serta berperan sebagai perpanjangan tangan dari BNPT dan pemerintah daerah. Agar bisa bersinergi dalam menjalankan amanat ini, BNPT menyelenggarakan pelatihan bagi pengurus FKPT. ${ }^{20}$

Dengan latar belakang seperti tersebut di atas, BNPT dan The Nusa Institut membentuk FKPT di provinsi Maluku. Pelantikan pengurus dilakukan oleh Deputi I BNPT Mayjen TNI Agus SB pada tanggal 27 September 2012 dihadiri oleh sejumlah pemangku kepentingan di Maluku, seperti pimpinan SKPD, tokoh masyarakat, tokoh agama dan tokoh pemuda. ${ }^{21}$ FKPT Maluku adalah FKPT ke-12 yang dibentuk oleh BNPT:

Awal sejarah terbentuknya FKPT adalah diadakannya dialog oleh BNPT dan The Nusa Institut. Pada waktu itu, BNPT dan The Nusa Institut mengundang kurang lebih 200 orang di Hotel Swisbell. Pada waktu itu diadakan pemilihan tim formatur. Dari 200 peserta terpilih 8 orang formatur yaitu terdiri dari pak Ibrahim Uluputy, waktu itu ketua Kepala Kesbangpol Provinsi Maluku, bapak Ade Manuhutu mewakili Gereja Protestan Maluku, bapak Sulaeman Angkotasan mewakili akademisi dari Universitas Pattimura, bapak Mannan Latuconsina, bapak Idris Latuconsina mewakili MUI Maluku dan Prof. Irfan Idris mewakili BNPT. $^{22}$

Pengurus pertama FKPT Maluku selanjutnya dipilih dan ditetapkan oleh tim formatur yang dibentuk oleh BNPT dan The Nusa Institut. Pada akhirnya terbentuk pengurus yang terdiri dari 8 orang dengan komposisi sebagai berikut.

\footnotetext{
${ }^{20} \mathrm{http}: / / \mathrm{www}$. kompasiana.com/imarosalina84/cegah-terorisme-tugas-strategis-fkpt_ 55d56fd7d87_a61d006eeef35, diakses 8 Agustus 2016.

${ }^{21}$ https://thenusainstitute.wordpress.com/agenda/the-nusa-institute-dan-bnptmeresmikan-fkpt-provinsi-maluku/, diakses 29 Juli 2016.

${ }^{22}$ Drs. H. Abdul Rahim Uluputty, M.H, Ketua FKPT Maluku, "wawancara," Ambon, 2 Agustus 2016.
} 


\section{Tahblím}

Vol. XIV, No. 2, Desember 2018

Tabel 1. Daftar Pengurus Pertama FKPT Maluku (tahun 2012)

\begin{tabular}{|l|l|l|l|}
\hline NO. & \multicolumn{1}{|c|}{ NAMA } & \multicolumn{1}{|c|}{ JABATAN } & \multicolumn{1}{|c|}{ PEKERJAAN } \\
\hline 1 & $\begin{array}{l}\text { Drs. H. Abdul Rahim } \\
\text { Uluputty, M.H }\end{array}$ & $\begin{array}{l}\text { Ketua } \\
\text { Kantan } \\
\text { Kesbangpolansi } \\
\text { Maluku }\end{array}$ \\
\hline 2 & Pdt. J. Manuhutu, S.Th, S.E & Sekretaris & Pendeta \\
\hline 3 & Fatimah Kilwo, S.Ag & Bendahara & - \\
\hline 4 & Dr. Abdul Rauf, M.Ag & $\begin{array}{l}\text { Kabid Agama, } \\
\text { Pendidikan dan } \\
\text { Dakwah }\end{array}$ & Dosen IAIN Ambon \\
\hline 5 & Jhon Karim Pattisahusiwa & $\begin{array}{l}\text { Kabid } \\
\text { Pemberdayaan } \\
\text { Ekonomi, } \\
\text { Sosial, Budaya, } \\
\text { dan Hukum }\end{array}$ & Dosen Univ, Pattimura \\
\hline 6 & Bartje Minanlarat & $\begin{array}{l}\text { Kabid } \\
\text { Pemberdayaan } \\
\text { Media Massa, } \\
\text { Humas dan } \\
\text { Sosialisasi }\end{array}$ & Wartawan RRI \\
\hline 7 & $\begin{array}{l}\text { Drs. Sulaiman Angkotasan, } \\
\text { M.Si }\end{array}$ & $\begin{array}{l}\text { Kabid } \\
\text { Pemberdayaan } \\
\text { Pemuda dan } \\
\text { Perempuan }\end{array}$ & Tokoh Pemuda Maluku \\
\hline
\end{tabular}

Sumber: Sekretariat FKPT Maluku

Setelah pengurus FKPT Maluku terbentuk, terjadi kekosongan kegiatan sebagaimana disampaikan oleh Sekretaris FKPT Maluku bahwa "hampir 1 tahun setelah pembentukannya bisa dikatakan tidak ada kegiatan sama sekali. Kegiatan pertama FKPT Maluku adalah mengikuti Rakor I FKPT di Yogyakarta pada tahun 2013. Dari situlah dimulai penyusunan kegiatan FKPT seluruh Indonesia." 23

Pada tahun 2014 terjadi perubahan pengurus FKPT Maluku sebagaimana disampaikan lebih lanjut oleh Sekretaris FKPT bahwa "pada tahun 2014 dilakukan perubahan pengurus karena salah seorang pengurus yakni Bapak Raja Siri Sori Islam

${ }^{23}$ Pdt. J. Manuhutu, S.Th, S.E, Sekretaris FKPT Maluku, “wawancara," Ambon 1Agustus 2016. 


\section{Tahkím}

Vol. XIV, No. 2, Desember 2018

yang merupakan Ketua Bidang Ekonom, meninggal dunia. Kemudian pak Mannan juga mundur karena menjadi ketua partai. Ibu Fatima mundur karena mengundurkan diri." ${ }^{24}$

Adapun komposisi pengurus FKPT setelah perubahan kepengurusan dapat dilihat pada tabel berikut ini.

Tabel 2. Daftar Pengurus Pertama FKPT Maluku (tahun 2012)

\begin{tabular}{|l|l|l|l|}
\hline NO. & \multicolumn{1}{|c|}{ NAMA } & \multicolumn{1}{|c|}{ JABATAN } & \multicolumn{1}{|c|}{ PEKERJAAN } \\
\hline 1 & $\begin{array}{l}\text { Drs. H. Abdul Rahim } \\
\text { Uluputty, M.H }\end{array}$ & $\begin{array}{l}\text { Ketua } \\
\text { Kantan } \\
\text { Kesbangpol } \\
\text { Maluku }\end{array}$ \\
\hline 2 & Pdt. J. Manuhutu, S.Th, S.E & Sekretaris \\
\hline 3 & Dr. Roswati Nurdin, MHI & Bendahara & Pendeta \\
\hline 4 & Dr. Abdul Rauf, M.Ag & $\begin{array}{l}\text { Kabid Agama, } \\
\text { Pendidikan dan } \\
\text { Dakwah }\end{array}$ & Dosen IAIN Ambon \\
\hline 5 & $\begin{array}{l}\text { Drs. Sulaiman Angkotasan, } \\
\text { M.Si }\end{array}$ & $\begin{array}{l}\text { Kabid Pemberdayaan } \\
\text { Ekonomi, Sosial, } \\
\text { Budaya, dan Hukum }\end{array}$ & Dosen Univ. Pattimura \\
\hline 6 & Bartje Minanlarat & $\begin{array}{l}\text { Kabid Pemberdayaan } \\
\text { Media Massa, Humas } \\
\text { dan Sosialisasi }\end{array}$ & Wartawan RRI \\
\hline 7 & Ishak Lalihun, S.Sos, M.Si & $\begin{array}{l}\text { Kabid Pemberdayaan } \\
\text { Pemuda } \\
\text { Perempuan dan }\end{array}$ & Dosen Univ, Pattimura \\
\hline 8 & Dr. Subair Abdullah, M.Si & $\begin{array}{l}\text { Kabid Kajian dan } \\
\text { Penelitian }\end{array}$ & Dosen IAIN Ambon \\
\hline
\end{tabular}

Sumber: Sekretariat FKPT Maluku

Selain itu, FKPT dalam aktivitasnya sehari-hari dibantu oleh kelompok tugas kesekretariatan 3 (tiga) orang.

Adapun visi dan misi FKPT adalah sebagai berikut.

Visi:

"FKPT Adalah tumbuhnya kesadaran masyarakat tentang ancaman dan bahaya terorisme dengan berbasis pada nilai kearifan lokal guna mewujudkan masyarakat indonesia yang damai"

Misi:

1. Membantu BNPT dan Pemerintah Daerah dalam mencegah penyebaran paham radikal terorisme;

${ }^{24}$ Ibid. 


\section{Tahkím}

Vol. XIV, No. 2, Desember 2018

2. Melakukan gerakan penyadaran atas ancaman dan bahaya terorisme didaerah secara berkelanjutan, terukur, dan sesuai dengan kearifan;

3. Meningkatkan kesadaran dan kewaspadaan dini di Daerah melalui penanaman dan pengamalan nilai-nilai Pancasila dan UUD 45;

4. Menumbuhkan kearifan lokal yang menghargai keragaman masyarakat di Daerah;

5. Mengkoordinasikan kegiatan-kegiatan dalam menghadapi bahaya terorisme dengan berbagai unsur masyarakat dan pemangkau kepentingan di Daerah.

\section{Tujuan:}

1. Tujuan FKPT adalah untuk mewujudkan masyarakat yang sadar dan paham terhadap ancaman dan bahaya terorisme dalam kehidupan bermasyarakat, berbangsa, dan bernegara;

2. Tujuan FKPT adalah memberikan pemahaman kepada masyarakat untuk menghadapi segala bentuk ancaman radikal terorisme;

3. Tujuan FKPT adalah untuk mencegah berkembangnya paham radikal terorisme di daerah.

Terkait dengan fungsi FKPT Maluku, menurut Ketua FKPT Maluku, FKPT berfungsi sebagai forum koordinasi yang dapat berfungsi untuk mendiskusikan berbagai persoalan dan sejumlah masalah terkait pencegahan terorisme di daerah. Menurutnya, untuk mencegah ancaman terorisme butuh kerjasama dan sinergitas dari berbagai pihak termasuk pemerintah daerah dan tokoh agama, tokoh masyarakat, tokoh pendidikan dan sejumlah unsur lainnya. Jelasnya, "forum ini fungsinya sangat positif untuk mencegah adanya ancaman gangguan terorisme. Saya juga mau sampaikan, pencegahan terorisme ini bukan hanya tugas polisi atau BNPT tapi menjadi tugas kita semua." 25

\section{Program-Program Deradikalisasi FKPT Maluku}

Program deradikalisasi oleh FKPT Maluku dilakukan secara bersinergi dengan BNPT. Penjelasan terkait program deradikalisasi oleh FKPT Maluku disampiakan oleh Ketua Bidang Penelitian FKPT Maluku, Dr. Subair Abdullah, M.Si bahwa:

Hampir semua kegiatan kita itu sosialisasi. Kecuali pembinaan mantan-mantan teroris yang telah keluar dari penjara. FKPT membina mantan teroris kurang lebih 50 orang. Sampai saat ini sudah 2 kali pertemuan dengan mereka. Pertemuan pertama di Hotel Swissbell pada tahun 2015 yang lalu. Mereka diinapkan di hotel selama dua hari. Semua mantan teroris diberi modal masing-masing Rp. 5.000.000,-. Tapi bukan berupa uang melainkan barang. Dia mau menjadi tukang ojek kita kasih uang muka motor. Dia mau buka toko kita belikan sembakonya. 5

\footnotetext{
${ }^{25}$ Drs. H. Abdul Rahim Uluputty, M.H, Ketua FKPT Maluku, “wawancara,” Ambon, 2 Agustus
} 2016. 


\section{Tahkím}

Vol. XIV, No. 2, Desember 2018

juta itu utuh. Pajaknya kita (BNPT) yang bayar. ... Pertemuan dibarengi dengan ceramah-ceramah tentang pemberdayaan dengan pemateri dari BNPT pusat." ${ }^{26}$

Lebih lanjut, Subair menjelaskan sebagai berikut.

Ada dua sebenarnya subjek pembinaan dalam hal ini yaitu mantan teroris itu sendiri dan keluarganya. Seperti istrinya Ongen, diikutsertakan karena suaminya kan masih di penjara di Jawa. Intinya bagaimana membangun dengan modal awal ini. Itu yang kita harapkan. Istrinya Ongen di Batu Merah. Ongen adalah terpidana teroris seumur hidup pada kasus pengeboman. Ada nama Soa. Dia minta motor ojek. Kita Dp-kan motor ojek. Ada nama Ancu di Batu Merah, minta alat kompresor untuk menyelam. Kita belikan. ${ }^{27}$

Para mantan teroris ini pada saat menerima bantuan tidak diminta untuk mengembalikan uang yang diberikan. Mereka juga tidak perlu membuat laporan penggunaan uang bantuan. Tetapi secara berkala BNPT melalui FKPT melakukan evaluasi dan pengawasan penggunaan bantuan. Konsekuensinya adalah kalau mereka tidak bisa memanfaatkan bantuan modal yang diberikan secara cumacuma itu maka bantuan tidak berlanjut. BNPT secara terus menerus melakukan evaluasi. $^{28}$

Terkait dengan program deradikalisasi seperti diuraikan di atas, Ketua FKPT menjelaskan sebagai berikut:

Deradikalisasi di Maluku itu adalah deradikalisasi di luar lapas karena tidak ada terpidana teroris di Lapas Ambon. Semua terpidana teroris ditahan di Lapas Porong. Jadi tidak ada deradikalisasi dalam lapas di sini, semuanya di luar lapas." 29

\section{a. Program Deradikalisasi secara Kelembagaan}

Daftar Kegiatan FKPT Maluku Periode 2013-2015

- 2013: Sosialisasi dan Dialog Hasil Penelitian tentang Narasi-narasi penyebaran radikalisme dan terorisme.

Capaian Kegiatan: Kegiatan dilaksanakan dalam bentuk diskusi sehari menghasilkan RTL pembentukan kelompok sel untuk mensosialisasikan anti radikalisme dan terorisme serta penyebaran pamplet pencegahan terorisme dan radikalisme sampai ke akar rumput (grasroot).

- 2014: 1. Pembentukan kelompok sel Pemuda di kota Ambon dan Maluku tengah; 2.

Sosialisasi dan dialog radikalisme dan terorisme bagi kelompok pemuda di kota

Ambon dan Maluku tengah.

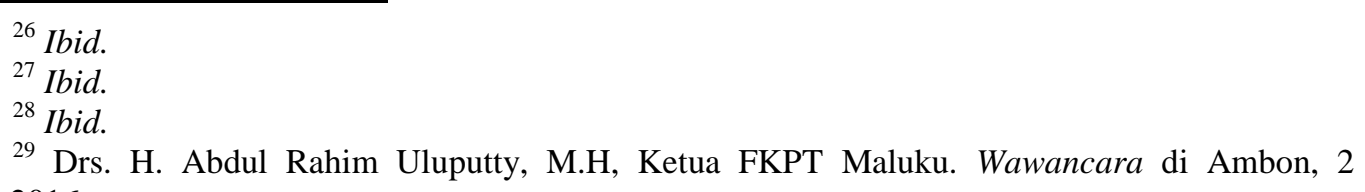
Agustus 2016. 


\section{Tahkím}

Vol. XIV, No. 2, Desember 2018

Capaian Kegiatan: 1. Terjadinya perubahan pemahaman tentang aksi radikalisme dan terorisme di Indonesia; 2.Memperoleh pengetahuan baru tentang agama dan terorisme serta dampak buruk radikalisme dan terorisme bagi kehidupan berbangsa dan bernegara serta bagi keutuhan Pancasila dan UUD 1945; 3.Adanya perubahan sikap dan perilaku yang ekslusif menjadi inklusif; 4.Pembuatan RTL untuk kegiatan lanjutan d masingmasing wilayah (Ambon dan Maluku Tengah)

- 2015: 1. Sosialisasi dan Dialog radikalisme dan terorisme bagi tokoh pendidik di Maluku; 2.Sosialisasi dan Dialog radikalisme dan terorisme bagi tokoh-tokoh agama; 3.Sosialisasi dan dialog radikalisme dan terorisme bagi pemuda dan perempuan,; 4.Sosialisasi dan dialog radikalisme dan terorisme bagi insan pers dan Hubmas kantor/Dinas; 5. FGD; 6.Pembahasan hasil penelitian tentang potensi terorisme di kota Ambon; 7.Penelitian tentang Radikalisme dan Terorisme di Kota Ambon.

Capaian Kegiatan:

- Guru SMP/SMA dan Dosen PT Maluku memperoleh pengetahuan baru tentang radikalisme dan terorisme. Lembaga pendidikan tinggi dan menengah merupkan tempat yang strategis dalam upaya sosialisasi radikalisme dan terorisme baik bagi dosen dan guru sebagai pendidik maupun bagi mahasiswa dan siswa. RTL bagi lembaga pendidikan tinggi dan menengah: Memasukkan sosialisasi radikalisme dan terorisme dalam muatan loka pada kurikulum SMA dan SMP; Sosialisasi melalui poster, leaflet dan I kaos berlogo anti terorisme untuk mahasiswa; Kegiatan champing atau outbond anti radikalisme bagi mahasiswa; Kegiatan sosialisasi anti radikalisme dan terorisme pada jambore siswa SMA dan SMP di tingkat provinsi Maluku.

- Tersosialisasinya masalah-masalah radikalisme dan terorisme di kalangan tokohtokoh agama secara merata. Agama dan budaya menjadi jembatan bagi penangkalan isu-isu radikal dan terorisme yang memecahbelah keomunitas agama di Maluku. Penyatuan langkah-langkah bersama agama-agama di Maluku terhadap upaya mencegah pertumbuhan radikalisme dan terorisme melalui khotbah Jumat dan Minggu. BNPT mengusulkan kepada Kementerian Pendidikan agar radikalisme dan terorisme dimasukkan dalam kurikulum mata pelajaran agama.

- Terbentuknya 10 kelompok pemuda dan perempuan di kota Ambon untuk menjadi motivator pencegahan radikalisme dan terorisme RTL: melakukan sosialisasi di kalangan perempuan di lingkungan tempat tinggal (RT, RW, dan kelompok arisan). Sosialisasi bahaya radikalisme dan terorisme bagi suami dan anak-anak dalam keluarga.

- Media massa dijadikan sarana sosialisasi anti radikalisme dan terorisme. Memanfaatkan ruang penulisan khotbah Jumat dan Minggu dengan isi khutbah yang muatannya berisi sosialisasi tentang radikalisme dan terorisme. Wartawan 


\section{Tahkím}

Vol. XIV, No. 2, Desember 2018

bertanggungjawab untuk menjadi penyalur informasi tentang pencegahan berkembangnya radikalisme dan terosrisme di masyarakat. Hubmas mensosialisasikan di lingkungan Dinas /Kantor dan instansi masing-masing. ${ }^{30}$

Dari beberapa kegiatan yang telah dilakukan seperti diuraikan di atas, FKPT Maluku menjadi andalan BNPT dalam memonitor pergerakan dan ancaman radikalisme dan terorisme di Maluku. Pada dasarnya seluruh kegiatan FKPT salah satunya dilakukan dalam rangka mencegah gerakan kelompok radikalisme dan terorisme agar tidak merasuki masyarakat Maluku.

Pertanyaannya selanjutnya adalah apakah kegiatan FKPT tersebut bisa dikategorikan sebagai kegiatan deradikalisasi? Menjawab pertanyaan ini, Ketua FKPT Maluku menjelaskan sebagai berikut:

Bisa ka seng katong hubungkan FKPT dengan deradikalisasi? Sebenarnya, intinya kita sosialisasi juga wadahnya adalah deradikalisasi. Jadi semuanya ada keterkaitan. Jadi ketika FKPT melakukan sosialisasi dan dialog ke masyarakat, di situlah sudah masuk deradikalisasi. Makanya ceramah-ceramah kita intinya bagaimana menghentikan. Stop itu radikalisme. Stop itu terorisme. ${ }^{31}$

Penjelasan serupa disampaikan oleh Ketua Bidang Penelitian FKPT Maluku.

FKPT itu berada di bawahnya pencegahan. FKPT itu di pencegahan. Berada di bawah Direktur Pencegahan BNPT. Direktur Deradikalisasi lain lagi. Tadinya FKPT awalnya berada dibawah direktorat Deradikalisasi. Tetapi muncul kemudian blue print, itu dia lari ke pencegahan. Jadi FKPT itu hanya berupaya mencegah supaya tidak menyeberang ke terorisme. ${ }^{32}$

\section{Pelibatan Pengurus FKPT dalam Program Deradikalisasi BNPT}

FKPT Maluku bersama BNPT sejak 2013 menjalankan deradikalisasi terhadap para napi teroris di lembaga pemasyarakatan (LP) yang menampung para napi teroris. Dalam merealisasikan program ini FKPT Maluku menjalin kerjasama dengan Kemenkumham, MUI, akademisi dan pihak pihak lain yang terkait untuk membantu membina para napi teroris untuk kembali ke jalan yang benar. Jelasnya, bahwa "kegitan ini bertujuan untuk menyapa mereka agar bertaubat, kelak setelah keluar dari LP dapat bersosialisasi dan membaur dengan lingkungan yang ada dan tak mengulangi masa lalunya."

Salah satu bentuk kegiatan pendekatan yang dilakukan FKPT Maluku, diantaranya dengan memfasilitasi upaya-upaya pembekalan ketrampilan praktis dan

\footnotetext{
${ }^{30}$ Sumber Sekretatriat FKPT Maluku

${ }^{31}$ Drs. H. Abdul Rahim Uluputty, M.H, Ketua FKPT Maluku, "wawancara," di Ambon, 2 Agustus 2016.

${ }^{32}$ Dr. H. Subair, M.Si, Ketua Bidang Penelitian FKPT Maluku, "wawancara," Ambon 2 September 2016
} 


\section{Tahkím}

Vol. XIV, No. 2, Desember 2018

kegiatan lainnya. FKPT Maluku mengajak kepada semua pihak untuk bergandengan tangan manyukseskan program ini. Yakni mengentaskan mereka dari belenggu tindak radikalisme dan terorisme.

Metode lain yang digunakan oeh FKPT dalam program deradikalisasi adalah dengan melibatkan dai di Maluku. Dai diharapkan bisa menjadi alat deradikalisasi dalam memberikan pemahaman agama Islam yang rahmatan lil alamin. Karena itu, dai menjadi faktor penting dalam penanggulangan terorisme di Indonesia. Hal itulah yang mendasari FKPT Maluku sebagai lembaga pemerintah yang menangani persoalan terorisme secara kontinyu melakukan pencegahan paham radikal-terorisme lewat dialog pelibatan dai. Dengan demikian "dialog peibatan ini merupakan upaya deradikalisasi pemahaman radikal terorisme yang mungkin saja berkembang di daerah Maluku, khususnya di Kota Ambon.",33

\section{Dampak Program Deradikalisasi}

Khusus di Maluku, menurut Ketua FKPT Maluku, program deradikalisasi sudah menunjukkan beberapa dampak yang positif. Lebih lanjut Ketua FKPT Maluku mengemukakan bahwa:

Kalau kita melihat, mereka sudah memahami bahwa ternyata tidak. Tetapi mereka pada dasarnya masih menyimpan pertanyaan: kenapa kami ditangkap padahal kami membawa bendera merah putih sedangkan mereka yang tidak membawa bendera merah putih dibiarkan lepas. Jadi mereka merasa didiskriminasi. Mereka kan mengatasnamakan melawan RMS tetapi kenapa yang ditangkap cuma mereka tetapi RMS dibebaskan.

Lebih lanjut, Ketua FKPT menjelaskan:

Selama pembinaan banyak mantan terorisme yang sebenarnya tidak setuju dengan program deradikalisasi BNPT. Terorisme itu kan ada empat macam atau kelompok. Ada yang tidak mau ketemu dan tidak mau berbicara. Ada yang mau bicara tetapi akidahnya tetap. Ini yang susah dua ini. Kelompok ketiga, mau bicara dan mau terbuka tetapi takut pada kelompok pertama dan kedua. Yang menjadi sasaran deradikalisasi adalah kelompok keempat yaitu kelompok yang mau bergabung seperti Ali Fauzi. Jadi masih ada memang yang tidak mau terlibat dalam program deradikalisasi, termasuk di Ambon juga. Yang diundang kan sebenarnya lebih dari 50 orang tetapi yang datang hanya 50 orang itu. Yang tidak mau datang itu banyaklah alasan mereka. Dianggap tidak mau bekerja sama. Misalnya ada yang datang ke Swisbell tetapi tidak mau masuk. Saya dekati mereka, saya bilang ambil uangnya tetapi tidak usah rubah akidahmu. Pada akhirnya setelah mengikuti materi, akhirnya dengan sukarela dia mau bergabung. Jadi kelihatannya yang tidak mau bergabung dengan kita itu adalah mereka yang

\footnotetext{
${ }^{33}$ Drs. H. Abdul Rahim Uluputty, M.H, Ketua FKPT Maluku, “wawancara,” Ambon, 2 Agustus 2016.
} 


\section{Tahkím}

Vol. XIV, No. 2, Desember 2018

tidak mau mendengar kita bicara. Dia kira dengan uang 5 juta itu akidahnya mau dibeli. Padahal kalau saya, ambil uangnya perkuat akidahmu." 34

\section{Kesimpulan}

Salah satu upaya yang dinilai ampuh untuk memberantas terorisme adalah dengan program deradikalisasi. Upaya mencegah terjadinya kekerasan beratasnamakan agama, itulah mengapa deradikalisasi menjadi penting. Karena agama pada dasarnya adalah mengajarkan kemoralan, kerohanian, akhlak mulia, lemah lembut, kedamaian. Bukan mengajarkan bentuk kekerasan, pembantaian apalagi pembunuhan. Deradikalisasi merupakan upaya menetralisir paham radikal bagi mereka yang terlibat teroris dan para simpatisannya serta anggota masyarakat yang telah terekspos pahampaham radikal, melalui reedukasi dan resosialisasi serta menanamkan multikuralisme. Langkah strategis dalam implementasi dan sosialisasi program deradikalisasi di daerah adalah dengan melibatkan organisasi-organisasi masyarakat sipil Indonesia, mengingat lingkungan sosial adalah locus utama bagi penyebaran benih-benih radikalisme. Dalam konteks inilah peran Forum Kordinasi Pencegahan Terorisme (FKPT) menjadi sangat strategis. Dengan melibatkan FKPT sebagai representasi publik/masyarakat sipil pelaksanaan program deradikalisasi menjadi lebih efektif dalam jangka panjang. Pelibatan FKPT dalam program deradikalisasi Badan Nasional Penanggulangan Terorisme (BNPT) di Maluku dilakukan pada seluruh kegiatan FKPT

\section{DAFTAR PUSTAKA}

Al-Asymawi, Muhammad Said. Al-Islam al-Siyasi, Kairo: Sina li al-Nasyr, 1987.

Al-Jabiri, Muhammad Abid. Agama, Negara dan Penerapan Syariah, Yogyakarta: Pustaka Pelajar, 2001.

Effendy, Bachtiar. Radikalisme: Sebuah Pengantar, Jakarta: PPIM, 1998.

Fealy, Greg and Virginia Hooker (ed.). Voices of Islam in Southeast Asia: A Contemporary Sourcebook, Singapore: ISEAS, 2006.

Hikam, Muhammad AS. Deradikalisasi: Peran Masyarakat Sipil Indonesia Membendung Radikalisme. Jakarta: Penerbit Buku Kompas, 2016.

http://www.kompasiana.com/imarosalina84/cegah-terorisme-tugas-strategis-fkpt_55d5 6fd7d87a61d006eeef35, diakses 8 Agustus 2016.

https://thenusainstitute.wordpress.com/agenda/the-nusa-institute-dan-bnpt-meresmikanfkpt-provinsi-maluku/, diakses 29 Juli 2016.

M., Marwan dan Jimmy P. Kamus Hukum, Surabaya: Reality Publisher, 2009

${ }^{34}$ Ibid 


\section{Tahkim}

Vol. XIV, No. 2, Desember 2018

Nasution, Harun. Islam Rasional. Bandung: Mizan. 1995.

Romli, Atmasasmita. “Deradikalisasi dan Tindak Pidana Terorisme”, Harian Seputar Indonesia, 25 April 2011.

Salim, Arskal dan Azyumardi Azra. "Introduction: The State and Shari'a in the Perspective of Indonesian Legal Politics," Sharia and Politics in Modern Indonesia, ed. Arskal Salim and Azyumardi Azra, Singapore: Institute of Southeast Asian Studies. 2003.

Sekretatriat FKPT Maluku.

Sidik, Jafar M. "Terorisme, Semiotika dan Bahasa Indonesia” dalam Kompas, 6 Oktober 2010.

Silber, Mitchell D and Arvin Bhatt. Radicalization in the West: The Homegrown Threat, New York : New York Police Department Intelligence Division, 2007.

Subair. Kapita Selekta Sosiologi Agama, Yogyakarta: Uswah Press dan Grha Guru, 2013. 